\title{
Astragaloside IV regulates NF-кB-mediated cellular senescence and apoptosis of hepatic stellate cells to suppress PDGF-BB-induced activation
}

\author{
ZHIWEI CHEN ${ }^{1}$, LING YAO $^{1}$, YUANYUAN LIU ${ }^{2}$, ZHENG PAN $^{1}$, SHUANG PENG $^{3}$, GUOGUO WAN ${ }^{1}$, \\ JUNXIONG CHENG ${ }^{1}$, JIANWEI WANG ${ }^{1}$ and WENFU CAO ${ }^{1,4}$ \\ ${ }^{1}$ Chongqing Key Laboratory of Traditional Chinese Medicine for Prevention and Cure of Metabolic Diseases, \\ College of Traditional Chinese Medicine, Chongqing Medical University, Chongqing 400016; \\ ${ }^{2}$ Department of Hematology, Southwest Hospital, Third Military Medical University (Army Medical University), \\ Chongqing 400038; ${ }^{3}$ Department of Intensive Care Unit, Chongqing Traditional Chinese Medicine Hospital, \\ Chongqing 400021; ${ }^{4}$ Department of Chinese Traditional Medicine, The First Affiliated Hospital of \\ Chongqing Medical University, Chongqing 400016, P.R. China
}

Received October 23, 2018; Accepted May 31, 2019

DOI: $10.3892 /$ etm.2019.8047

\begin{abstract}
Activated hepatic stellate cells (HSCs) are the principal effectors during hepatic fibrosis, which is characterized by the accumulation of extracellular matrix. Therefore, present therapies and investigations into hepatic fibrosis mainly focus on the suppression of activated HSCs. Astragaloside IV (ASIV) is an effective constituent extracted from the plant Astragalus membranaceus and has exhibited anti-fibrotic properties in hepatic fibrosis. However, its protective mechanism against hepatic fibrosis is not fully understood. The present study aimed to investigate the mechanistic role of ASIV on rat HSC-T6 cells activated with platelet-derived growth factor (PDGF)-BB. HSC-T6 cells were activated using PDGF-BB and subsequently treated with ASIV (final concentrations of 20 and $40 \mu \mathrm{g} / \mathrm{ml}$ ) for $48 \mathrm{~h}$. ASIV treatment decreased the expression of $\alpha 1$ type I collagen, $\alpha$-smooth muscle actin and fibronectin on mRNA and protein levels, suggesting that ASIV suppresses PDGF-BB-induced HSC-T6 activation. Senescence-associated $\beta$-galactosidase activity, $\mathrm{p} 21$, high-mobility group AT-hook 1 and p53, common biomarkers of senescence, were upregulated by ASIV treatment. In addition, the expression of telomerase reverse transcriptase was reduced. ASIV promoted apoptosis of PDGF-BB-activated HSC-T6 cells. The NF- $\kappa \mathrm{B}$ signaling pathway, which controls cellular senescence and apoptosis,
\end{abstract}

Correspondence to: Professor Wenfu Cao, Chongqing Key Laboratory of Traditional Chinese Medicine for Prevention and Cure of Metabolic Diseases, College of Traditional Chinese Medicine, Chongqing Medical University, 1 Yixueyuan Road, Yuzhong, Chongqing 400016, P.R. China

E-mail: 13883658367@163.com

Key words: astragaloside IV, hepatic stellate cells, cellular senescence, apoptosis, nuclear factor- $\kappa \mathrm{B}$ pathway was demonstrated to be stimulated by ASIV by increasing p65, p52, p50 and inhibitor of NF- $\mathrm{\kappa B}$ kinase $\alpha$ expression levels, and by suppressing the expression of NF- $\kappa \mathrm{B}$ inhibitor $\alpha$. Taken together, these results demonstrated that ASIV promoted cellular senescence and apoptosis by activating the $\mathrm{NF}-\kappa \mathrm{B}$ pathway to suppress PDGF-BB-induced HSC-T6 activation; with potential implications for the treatment of hepatic fibrosis.

\section{Introduction}

Hepatic fibrosis is a common pathological feature of various chronic liver diseases, including viral hepatitis, alcoholic liver disease and non-alcoholic fatty liver disease (1). If untreated, hepatic fibrosis ultimately develops into liver cirrhosis or hepatocellular carcinoma (2). In the normal liver, most hepatic stellate cells (HSCs) are in a quiescent state to maintain a balance between synthesis and degradation of the fibrillary extracellular matrix (ECM) (3). Hepatic fibrosis is characterized by the progressive secretion and accumulation of ECM by activated HSCs (4). A previous study demonstrated that liver injury or culturing in vitro will result in HSC activation and lead to the excessive accumulation of ECM components, including fibronectin (FN) and various types of collagens (5). In addition, a number of chemokines, cytokines and growth factors have been reported to contribute to HSC activation (6). In particular, the platelet-derived growth factor (PDGF) family is one of the most effective inducers of HSC activation, which further exacerbates hepatic fibrosis (7).

Induction of activated HSC senescence, apoptosis and reversion to the quiescent state has been reported to facilitate the interruption of hepatic fibrosis $(8,9)$. Senescent cells display a large and flat morphology, exhibit upregulated p21, p53 and HMGA1 expression (10), and exhibit enhanced senescence-associated $\beta$-galactosidase (SA- $\beta$-gal) activity (11). During senescence, p21 expression is increased and activated, which act as an inhibitor to cyclin-dependent kinases, to arrest cell cycle progression (12). In addition, 
high-mobility group AT-hook 1 (HMGA) proteins accumulate on the chromatin of senescent fibroblasts to stabilize the senescent state by synergizing with p16 (13). In terms of transcription, p53 is upregulated and cooperates with $\mathrm{NF}-\kappa \mathrm{B}$ to promote cellular senescence (14). The activation of $\mathrm{NF}-\kappa \mathrm{B}$ transcription factors serves as a driver for the ageing process (15). Telomerase reverse transcriptase (TERT), the catalytic subunit of telomerase, elongates telomeres and maintains their structures. However, declined activity or expression of TERT shortens telomeres leading to senescence (16). Activated HSCs can be depleted by the activation of programmed cell death. Apoptotic cells undergo various morphological changes, including cell shrinkage and convolution, pyknosis and karyorrhexis (17). Phosphatidylserine translocation to the cell surface is another apoptotic feature that has been exploited for the detection of apoptosis (18). Activated HSCs can also be reverted to a deactivated intermediate semi-quiescent state to reduce ECM accumulation (19). Therefore, investigations into determining the cell fate of activated HSCs have become a focus of intense research for alleviating or reversing hepatic fibrosis.

Astragalus membranaceus is one of the most commonly used Traditional Chinese Medicine for hepatic fibrosis treatment in China (20). Astragaloside IV (ASIV) is the major active constituent of A. membranaceus. At present, the degree of ASIV content is an important parameter for the evaluation of A. membranaceus quality (21). Previous in vitro and in vivo studies have indicated that ASIV possesses a variety of cytoprotective properties, including anti-oxidative $(22,23)$ and anti-cancer $(24,25)$, in addition to some anti-fibrotic roles in pulmonary $(26,27)$, cardiac $(28,29)$, renal $(30,31)$ and hepatic fibrosis (32). However, the molecular mechanism of ASIV-mediated anti-fibrosis remains poorly understood.

The present study aimed to investigate the protective mechanisms of ASIV on activated HSCs by using a PDGF-BB-activated rat HSC-T6 cell line as a model. Reverse transcription-quantitative PCR (RT-qPCR), western blotting and immunofluorescence staining were performed to evaluate the expression of fibrotic and senescence markers, and components of the NF- $\kappa \mathrm{B}$ signal pathway. SA- $\beta$-gal staining was implemented to determine the degree of senescence at various concentrations of ASIV. Flow cytometry was used for the analysis of apoptosis in activated HSCs. In conclusion, it was demonstrated that ASIV treatment suppressed PDGF-BB-induced HSC activation by activating the $\mathrm{NF}-\kappa \mathrm{B}$ signaling pathway and promoting cellular senescence and apoptosis. These data may provide new insights into the cell fate determination of PDGF-BB-activated HSCs and implicated ASIV as a potential treatment strategy for hepatic fibrosis.

\section{Materials and methods}

Reagents. DMEM, FBS, trypsin, penicillin-streptomycin (100X) were purchased from Biological Industries. ASIV was purchased from Beijing Solarbio Science \& Technology Co., Ltd. (purity $\geq 98 \%$, HPLC). The chemical structure of ASIV $\left(\mathrm{C}_{41} \mathrm{H}_{68} \mathrm{O}_{14}\right.$; molecular weight, 784.97$)$ is illustrated in Fig. 1. Rat PDGF-BB was purchased from GenScript. Gene-specific primers were synthesized by TsingKe Biological Technology
Co., Ltd. DMSO was purchased from Sigma-Aldrich (Merck KGaA).

Cell culture and ASIV treatment. The rat HSC line HSC-T6 was obtained from Procell Life Science \& Technology Co., Ltd. The cells were cultured using DMEM supplemented with $10 \%$ (v/v) FBS and $100 \mu \mathrm{g} / \mathrm{ml}$ penicillin-streptomycin at $37^{\circ} \mathrm{C}$ under $5 \% \mathrm{CO}_{2}$. HSC-T6 cells were activated using PDGF-BB at a final concentration of $20 \mathrm{ng} / \mathrm{ml}$, as previously reported (33). ASIV powder was first dissolved in DMSO and subsequently diluted in DMEM to a final concentration of 0 , 20 and $40 \mu \mathrm{g} / \mathrm{ml}$ (34). The final concentration of DMSO was not in excess of $0.1 \%(\mathrm{v} / \mathrm{v})$.

Immunofluorescence staining. HSC-T6 cells were seeded onto coverslips placed in 24-well plates at $2 \times 10^{3}$ cells/well at $37^{\circ} \mathrm{C}$ for $12 \mathrm{~h}$ prior to treatment with PDGF-BB and ASIV for $48 \mathrm{~h}$. Following drug treatment, the coverslips were rinsed three times with $1 \mathrm{X}$ PBS for $5 \mathrm{~min}$ each, before fixation in $4 \%$ paraformaldehyde for $30 \mathrm{~min}$ at room temperature. Then, $0.2 \%$ Triton X-100 (Beijing Solarbio Science \& Technology Co., Ltd.) was used to permeabilize cells for $10 \mathrm{~min}$ at room temperature. After blocking with 5\% BSA (Beyotime Institute of Biotechnology) for $30 \mathrm{~min}$ at room temperature, the coverslips were subsequently treated with primary antibodies (1:100) for $2 \mathrm{~h}$ at room temperature. The primary antibodies used were as follows: Collagen type I $\alpha 1$ (COL1A1; cat. no. ab6308; Abcam), $\alpha$-smooth muscle actin ( $\alpha$-SMA; cat. no. MAB1420; R\&D Systems, Inc.) and fibronectin (FN; cat. no. AF5335; Affinity Biosciences). Cells were washed three times with $1 \mathrm{X}$ PBS, and the coverslips were incubated with $\mathrm{Cy}^{\circledR} 3$-conjugated secondary antibodies (1:200; cat. no. E031620-01; EarthOx Life Sciences) for $1 \mathrm{~h}$ at room temperature. After another rinsing three times with $1 \mathrm{X}$ PBS, cells were finally stained using $10 \mu \mathrm{g} / \mathrm{ml}$ DAPI (Beijing 4A Biotech Co., Ltd.) for $30 \mathrm{~min}$ at room temperature for microscopic analysis using upright fluorescence microscopes at $\mathrm{x} 10$ eyepiece and $\mathrm{x} 20$ objective lens.

RNA isolation and RT-qPCR. HSC-T6 cells were seeded in 12 -well plates at a density of $5 \times 10^{4}$ cells/well. Following a 12-h culture, cells were treated with PDGF-BB and ASIV for $48 \mathrm{~h}$. Total RNA was extracted from HSC-T6 cells using RNAiso Plus reagent (Takara Bio, Inc.), according to manufacturer's protocols. A total of $500 \mathrm{ng}$ total RNA was reverse-transcribed into cDNA using PrimeScript ${ }^{\mathrm{TM}}$ RT Master Mix (Takara Bio, Inc.). RT reaction steps consisted of $37^{\circ} \mathrm{C}$ for $15 \mathrm{~min}$ and $85^{\circ} \mathrm{C}$ for $5 \mathrm{sec}$. Gene specific primers were designed using NCBI Primer-BLAST (https://www.ncbi.nlm.nih. gov/tools/primer-blast) and are listed in Table I. qPCR analysis was performed in a Bio-Rad CFX96 Real-Time PCR Detection System (Bio-Rad Laboratories, Inc.) using TB Green ${ }^{\mathrm{TM}}$ Premix $\mathrm{Ex} \mathrm{Taq}^{\mathrm{TM}}$ (Takara Bio, Inc.). The qPCR cycling conditions were as follows: $30 \mathrm{sec}$ at $95^{\circ} \mathrm{C}$, and 40 cycles of $10 \mathrm{sec}$ at $95^{\circ} \mathrm{C}$, $30 \mathrm{sec}$ at $60^{\circ} \mathrm{C}$ and $20 \mathrm{sec}$ at $72^{\circ} \mathrm{C}$. Relative gene expression was quantified using the $2^{-\Delta \Delta \mathrm{Cq}}$ method (35). GAPDH was used as internal control.

Western blot analysis. HSC-T6 cells were seeded in 6-well plates at a density of $2 \times 10^{5}$ cells/well. Following a $12-\mathrm{h}$ culture, cells were treated with PDGF-BB and ASIV for $48 \mathrm{~h}$. 
Table I. Primers used for reverse transcription-quantitative PCR.

\begin{tabular}{|c|c|c|}
\hline Gene & Forward primer $\left(5^{\prime}-3^{\prime}\right)$ & $\begin{array}{l}\text { Product } \\
\text { size }(b p)\end{array}$ \\
\hline GAPDH & $\begin{array}{l}\text { F: TTCAACGGCACAGTCAAGG } \\
\text { R: CTCAGCACCAGCATCACC }\end{array}$ & 114 \\
\hline COL1A1 & $\begin{array}{l}\text { F: GGAGAGAGCATGACCGATGG } \\
\text { R: GGGACTTCTTGAGGTTGCCA }\end{array}$ & 184 \\
\hline$\alpha-\mathrm{SMA}$ & $\begin{array}{l}\text { F: CGAAGCGCAGAGCAAGAGA } \\
\text { R: CATGTCGTCCCAGTTGGTGAT }\end{array}$ & 78 \\
\hline FN & $\begin{array}{l}\text { F: TGGAGAGACAGGAGGAAATAGC } \\
\text { R: CAGTGACAGCATACAGGGTGAT }\end{array}$ & 122 \\
\hline p65 & $\begin{array}{l}\text { F: CCTGGAGCAAGCCATTAGCC } \\
\text { R: CGGACCGCATTCAAGTCATAGT }\end{array}$ & 99 \\
\hline p52 & $\begin{array}{l}\text { F: GGTCACCAAGCTCCATGCTA } \\
\text { R: GGTTGGGGATCCAAGTCCAG }\end{array}$ & 88 \\
\hline p50 & $\begin{array}{l}\text { F: TCTCTATGACCTGGACGACTC } \\
\text { R: AGAGTTGCAGCCTCGTGTC }\end{array}$ & 202 \\
\hline HMGA1 & $\begin{array}{l}\text { F: CAGGAAAAGGATGGGACTGA } \\
\text { R: CTTGTTCTTGCTTCCCTTCG }\end{array}$ & 156 \\
\hline p21 & $\begin{array}{l}\text { F: GAGCAAAGTATGCCGTCGTC } \\
\text { R: CTCAGTGGCGAAGTCAAAGTTC }\end{array}$ & 127 \\
\hline p53 & $\begin{array}{l}\text { F: ATATTCTGCCCACCACAGCG } \\
\text { R: CACTTGGAGGGCTTCCTCTG }\end{array}$ & 107 \\
\hline RelB & $\begin{array}{l}\text { F: TTGTGGTCCAGCACTCCATC } \\
\text { R: CACCCCATCTCAACAGCACT }\end{array}$ & 96 \\
\hline c-Rel & $\begin{array}{l}\text { F: CAGGCACCAGTTCCAGTTCT } \\
\text { R: GTGCGTCGTTTGCTAATCCG }\end{array}$ & 114 \\
\hline TERT & $\begin{array}{l}\text { F: TTTCGAACAGCAAACCAGCG } \\
\text { R: GCTGTGTAACCGGAGCAAAC }\end{array}$ & 81 \\
\hline
\end{tabular}

$\alpha$-SMA, $\alpha$-smooth muscle actin; COL1A1, $\alpha 1$ type I collagen; FN, fibronectin; HMGA, high-mobility group AT-hook 1; TERT, telomerase reverse transcriptase; $\mathrm{F}$, forward; $\mathrm{R}$, reverse.

Total cellular protein from HSC-T6 cells was extracted using RIPA lysis buffer (Beyotime Institute of Biotechnology), and protein concentration was determined using bicinchoninic acid protein assay kit (Beyotime Institute of Biotechnology). Proteins (40 $\mu \mathrm{g} /$ lane) were separated using 10\% SDS-PAGE, and subsequently transferred to PVDF membranes. The membranes were blocked for $2 \mathrm{~h}$ at room temperature with 5\% skimmed milk powder dissolved in Tris-buffered saline containing $0.1 \%$ Tween-20. Following blocking the membranes were incubated with primary antibodies $(1: 1,000)$ in $5 \%$ skimmed milk overnight at $4^{\circ} \mathrm{C}$. The primary antibodies used were as follows: $\alpha$-smooth muscle actin ( $\alpha$-SMA; cat. no. MAB1420; R\&D Systems, Inc.), FN (cat. no. AF5335; Affinity Biosciences), GAPDH (E021060-03; EarthOx Life Sciences), HMGA1 (cat. no. ab129153; Abcam), p21 (cat. no. ab109199; Abcam), p65 (cat. no. AF6387; Affinity Biosciences), p52 (cat. no. AF6373; Affinity Biosciences) and NF- $\kappa$ B inhibitor $\alpha(\mathrm{I} \kappa \mathrm{B} \alpha$; cat. no. NB100-56507; Novus Biologicals, Ltd.). Following primary antibody incubation, the membranes were washed five times with Tris-buffered

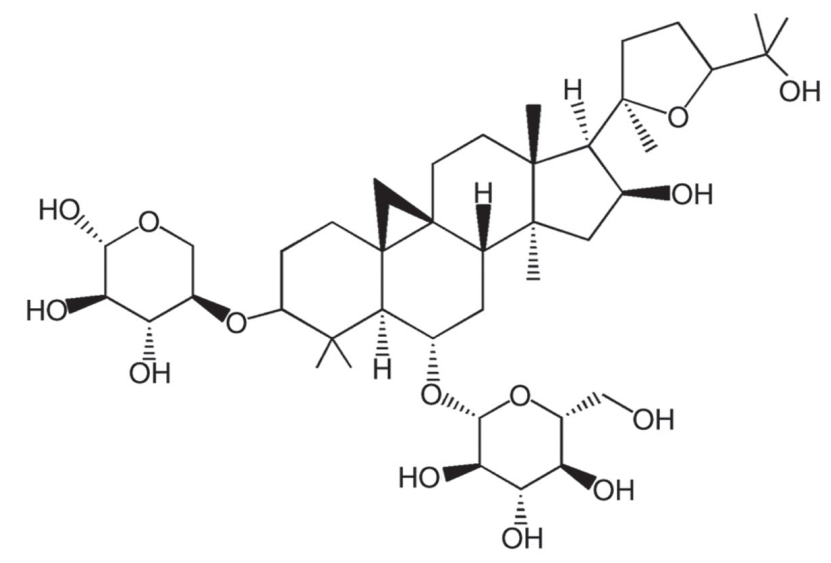

Figure 1. Chemical structure of astragaloside IV.

saline containing $0.1 \%$ Tween-20. Then membranes were subsequently incubated with horseradish peroxidase (HRP)-conjugated goat anti-rabbit immunoglobulin (Ig)G (cat. no. E030120-01; 1:10,000; EarthOx Life Sciences) and HRP-conjugated goat anti-mouse IgG (cat. no. GB23301; 1:4,000; Wuhan Goodbio Technology Co.,Ltd.) in 1\% skimmed milk at room temperature for $1 \mathrm{~h}$, then the membranes were washed three times with Tris-buffered saline containing $0.1 \%$ Tween-20. Finally, the protein bands were visualized using UltraSignal Maximum Sensitivity ECL Substrate (Beijing 4A Biotech Co., Ltd.) and detected using an imaging system (Odyssey Fc Imaging System; Gene Company Ltd.). GAPDH was used as the internal control.

$S A$ - $\beta$-gal staining. HSC-T6 cells were seeded into 6-well plates at $6 \times 10^{4}$ cells/well prior to treatment with PDGF-BB and ASIV for $48 \mathrm{~h}$. SA- $\beta$-gal activity, a marker of senescence, was evaluated using the SA- $\beta$-gal Staining kit (Beyotime Institute of Biotechnology), according to the manufacturer's protocols.

Flow cytometry analysis of apoptosis. Apoptosis analysis was performed using Annexin V/PI assay kit (Invitrogen; Thermo Fisher Scientific, Inc.) according to manufacturer's protocols. Briefly, HSC-T6 cells treated with $20 \mathrm{ng} / \mathrm{ml}$ PDGF-BB and ASIV $(0$ or $40 \mu \mathrm{g} / \mathrm{ml})$ for $48 \mathrm{~h}$, and then cells were collected for cell counting. A total of $1 \times 10^{6}$ cells were rinsed once using ice-cold PBS and then with $1 \mathrm{X}$ Annexin V binding buffer, before being subsequently suspended in $100 \mu$ l binding buffer containing $5 \mu \mathrm{l}$ Annexin V-Allophycocyanin (APC) and $5 \mu$ propidium iodide (PI) followed by incubation at room temperature for $15 \mathrm{~min}$. Finally the cells were detected using a flow cytometer no more than $30 \mathrm{~min}$ after the incubation. The data were analyzed by FlowJo V10 (Expert Cytometry).

Statistical analysis. All data were presented as mean \pm standard deviation. All statistical analyses were performed using GraphPad Prism software 5.0 (GraphPad Software, Inc.). A two-tailed t-test was performed to assess differences between two data groups. One-way ANOVA followed by Newman-Keuls' post hoc test was used to compare differences between $>2$ data groups. $\mathrm{P}<0.05$ was considered to indicate a statistically significant difference. 
A

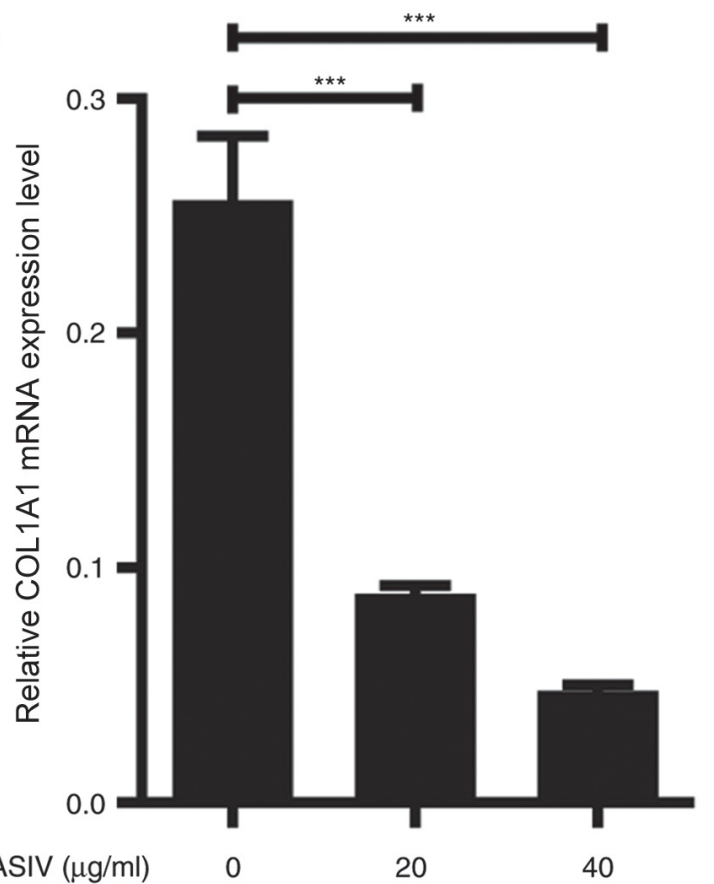

C

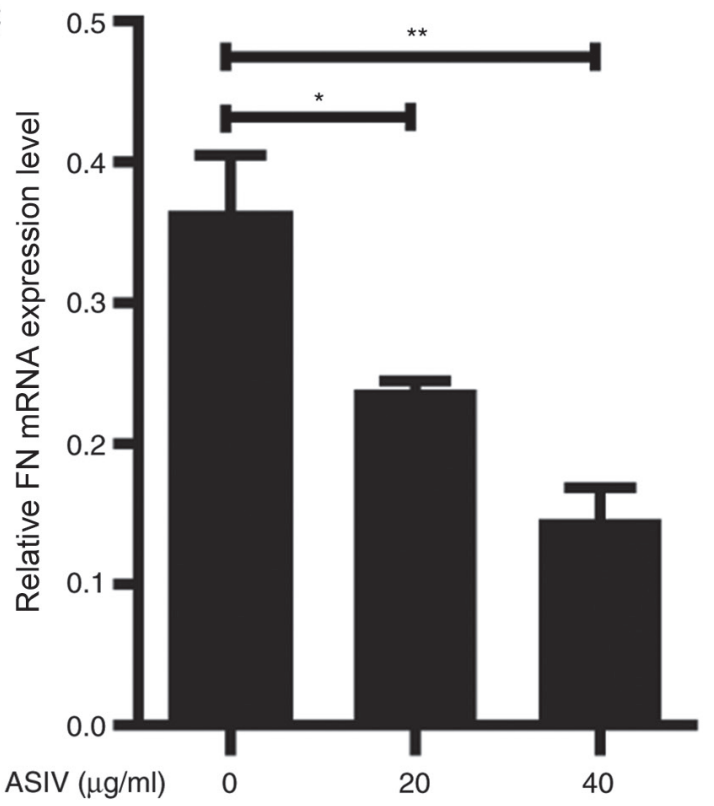

B

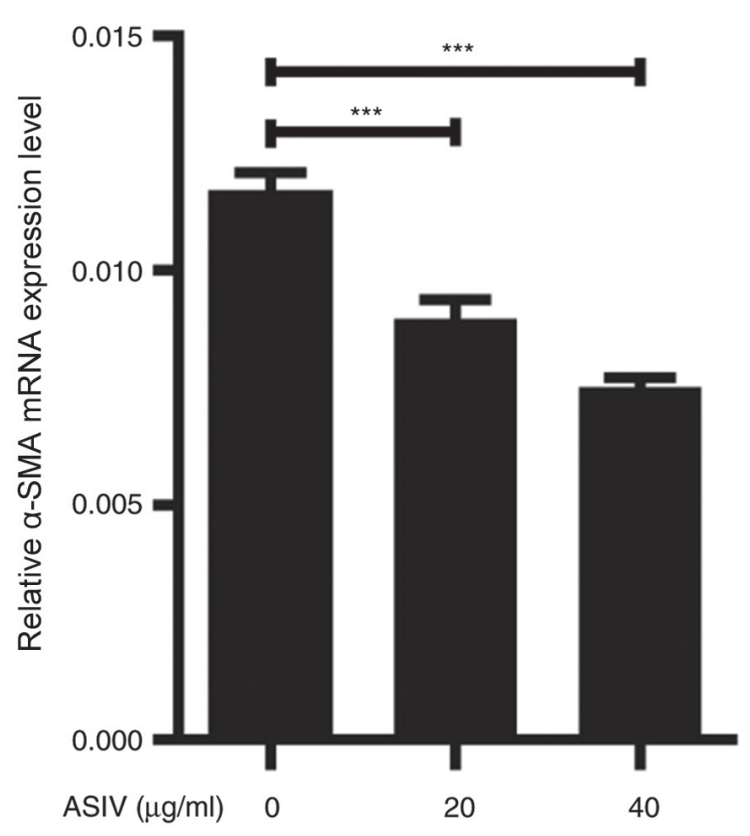

D

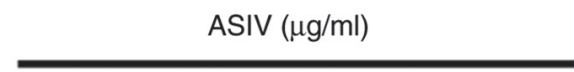

0

20

40

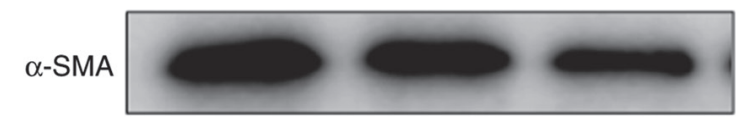

FN

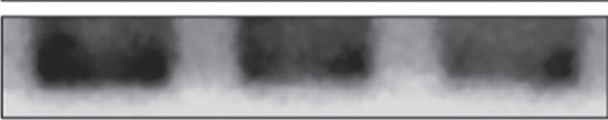

GAPDH

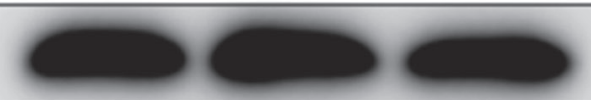

Figure 2. The expression of fibrosis markers in platelet-derived growth factor-BB-activated HSC-T6 treated with ASIV. The relative expressions of (A) COL1A1, (B) $\alpha$-SMA and (C) FN mRNA. (D) Protein expression level of $\alpha$-SMA and FN following ASIV treatment. ${ }^{*} \mathrm{P}<0.05,{ }^{* *} \mathrm{P}<0.01$ and ${ }^{* * * *} \mathrm{P}<0.001 . \alpha$-SMA, $\alpha$-smooth muscle actin; ASIV, astragaloside IV; COL1A1, $\alpha 1$ type I collagen; FN, fibronectin.

\section{Results}

ASIV suppresses ECM expression in PDGF-BB-activated $H S C$-T6. Hepatic fibrosis is characterized by the excessive secretion and accumulation of ECM by activated HSCs (36). ECM components, mainly including $\alpha$-SMA, COL1A1 and $\mathrm{FN}$, were used as the marker for HSC activation. Therefore, the present study aimed to investigate the effects of ASIV on HSC activation. PDGF-BB-activated HSC-T6 were treated with varying concentrations of ASIV $(0,20$ or $40 \mu \mathrm{g} / \mathrm{ml})$ for $48 \mathrm{~h}$. The expression levels of COL1A1, $\alpha$-SMA and FN were subsequently measured using RT-qPCR, western blotting or immunofluorescence staining. The relative mRNA expression levels of COL1A1, $\alpha$-SMA and FN mRNA were significantly reduced following ASIV treatment in a dose-dependent manner compared with untreated cells (Fig. 2A-C). On the protein level, data from western blot analysis and immunofluorescence showed that ASVI treatment downregulated the expression of COL1A1, $\alpha$-SMA and FN in HSC-T6. (Figs. 2D and 3).

ASIV promotes cellular senescence in PDGF-BB-activated $H S C$-T6. Induction of cellular senescence in activated HSCs would be beneficial to the prevention of hepatic fibrosis (37). Therefore, the activity of SA- $\beta$-gal, a common biomarker of senescence, was measured in activated HSCs in the presence of ASIV. Following ASIV treatment, SA- $\beta$-gal activity was 


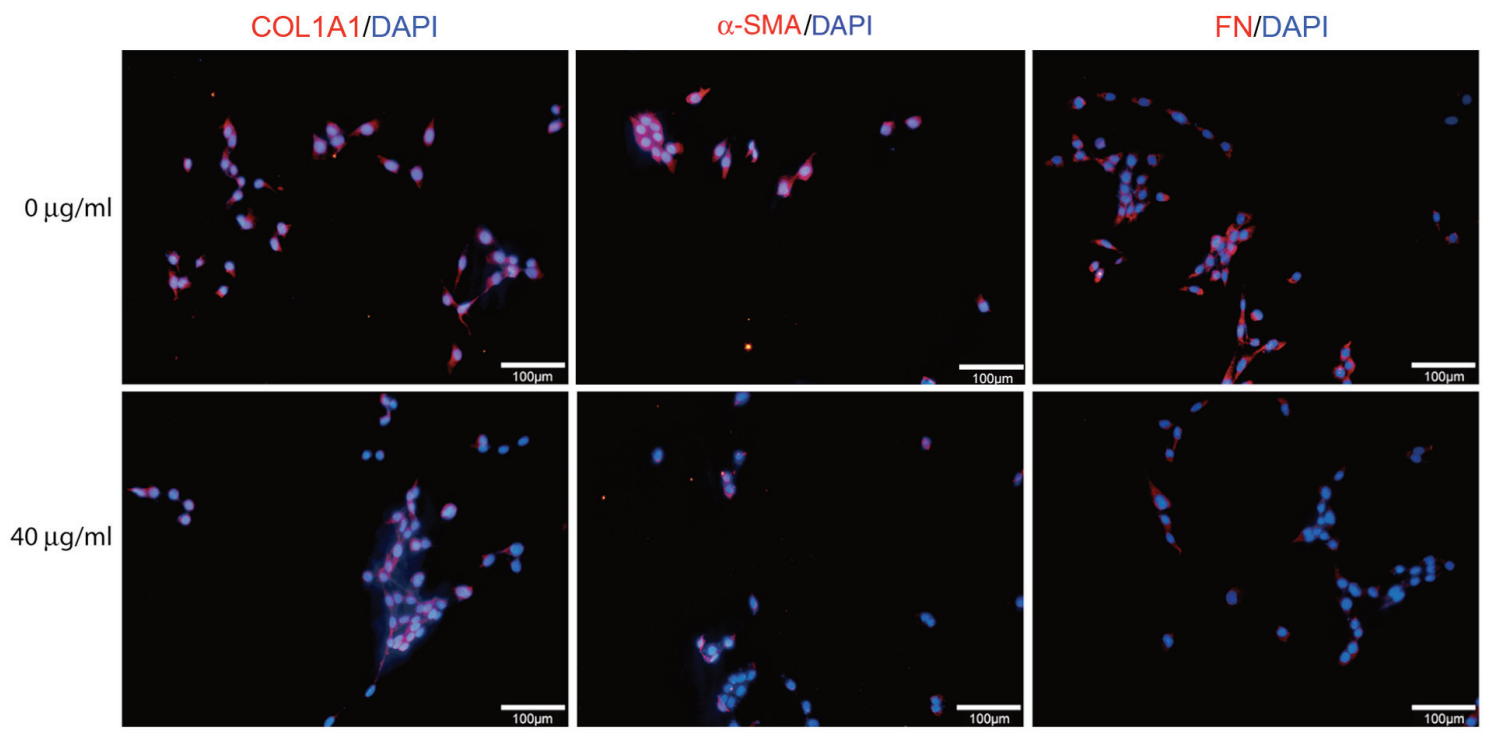

Figure 3. Immunofluorescence staining of COL1A1, $\alpha$-SMA and FN. Platelet-derived growth factor-BB-activated HSC-T6 were treated with 0 or $40 \mu \mathrm{g} / \mathrm{ml}$ ASIV prior to staining. The nuclei were stained using DAPI (blue), whereas proteins were detected using Cy3 (red). Scale bar, $100 \mu \mathrm{m}$. $\alpha$-SMA, $\alpha$-smooth muscle actin; ASIV, astragaloside IV; COL1A1, $\alpha 1$ type I collagen; FN, fibronectin.

revealed to be significantly enhanced in PDGF-BB-activated HSC-T6 (Fig. 4A and B). Supporting this, mRNA of senescence markers, p21, p53 and HMGA1 was significantly upregulated (Fig. 4C-E), while the protein expression of p53 and HMGA1 were markedly upregulated (Fig. 4G). Conversely, the corresponding mRNA levels of TERT were significantly reduced by ASIV treatment (Fig. 4F). In addition, all the observations made in this analysis appeared to display a dose-dependent trend compared with the untreated control (Fig. 4). These results suggest that ASIV treatment promoted senescence in activated HSC-T6.

ASIV induces apoptosis in PDGF-BB-activated HSC-T6. Apoptosis of activated HSCs contributed to the resolution of hepatic fibrosis (38). To investigate the effect of ASIV on the survival of PDGF-BB-activated HSC-T6, apoptosis was measured using flow-cytometry. The percentage of early and late apoptotic cells was revealed to be 2-3 times higher in the ASIV treatment group compared with the control group (Fig. 5A-C). At the same time, the result from flow-cytometry indicated that ASIV did not affect the necrotic cell death in PDGF-BB-activated HSC-T6 (Fig. 5A). These data support the notion that ASIV treatment accelerated apoptosis in addition to promoting cellular senescence in activated HSC-T6.

$A S I V$ regulates the $N F-\kappa B$ signaling pathway in PDGF-BBactivated HSC-T6. The NF- $\mathrm{NB}$ signaling pathway is involved in significant physiological and biochemical processes including cellular senescence and apoptosis $(39,40)$. To investigate the relationship between $\mathrm{NF}-\kappa \mathrm{B}$ signaling and PDGF-BB-activated HSC-T6 in the presence of ASIV, expression levels of p65, p52 and p50, components of the NF- $\kappa \mathrm{B}$ protein family, were analyzed. On mRNA level, p65, p52 and p50 were significantly upregulated by ASIV treatment in a dose-dependent manner (Fig. 6A-C), whereas RelB and c-Rel mRNA expression were not detectable in HSC-T6 using RT-qPCR. Western blot analysis appeared to support the upregulation of p65 and p52 on protein level in PDGF-BB-activated HSC-T6 (Fig. 6F). To investigate the effect of ASIV on the NF- $\kappa \mathrm{B}$ signaling pathway further, the expression levels of I $\kappa \mathrm{K} \alpha$ and $\mathrm{I} \kappa \mathrm{B} \alpha$, upstream regulatory components of the signaling pathway, were measured. RT-qPCR results revealed that ASIV treatment increased I $\kappa \mathrm{K} \alpha \mathrm{mRNA}$ expression and decreased I $\kappa \mathrm{B} \alpha \mathrm{mRNA}$ expression (Fig. 6D and E, respectively). ASIV also reduced $\mathrm{I} \kappa \mathrm{B} \alpha$ protein expression, according western blot analysis (Fig. 6F).

\section{Discussion}

The activation of HSCs marks a significant event in the hepatic fibrosis process. Activated HSCs adversely disrupt the balance between ECM production and proteolysis due to decreased expression of matrix metalloproteinases and increased expression of tissue inhibitors of metalloproteinases (37). Large amounts of collagen (types I, III, IV, V and VI), $\alpha$-SMA and FN are deposited by activated HSCs. If the suppression of HSC activation can be achieved, the degree of hepatic fibrosis could be considerably reduced or even reversed (41). Therefore, investigations into inhibiting HSC activation have become hotspots of research into hepatic fibrosis. In the present study, ASIV treatment downregulated the expression of fibrosis markers COL1A1, $\alpha$-SMA and FN to suppress PDGF-BB-induced HSC-T6 activation. Indeed, previous studies demonstrated that ASIV inhibited collagen synthesis in activated HSCs by regulating p38 MAPK pathway $(32,34)$. Evidence presented above demonstrated that ASIV can suppress a variety of factors leading to HSCs activation. As the principal mediator of hepatic fibrosis, data in the present study indicated ASIV could be used as a potentially therapeutic agent for hepatic fibrosis treatment.

Induction of cellular senescence and apoptosis are the most effective methods of inhibiting HSC activation and alleviating hepatic fibrosis (37). During the senescence process, cell proliferation and ECM expression become suppressed in activated HSCs (36). Further evidence exists demonstrating 
A
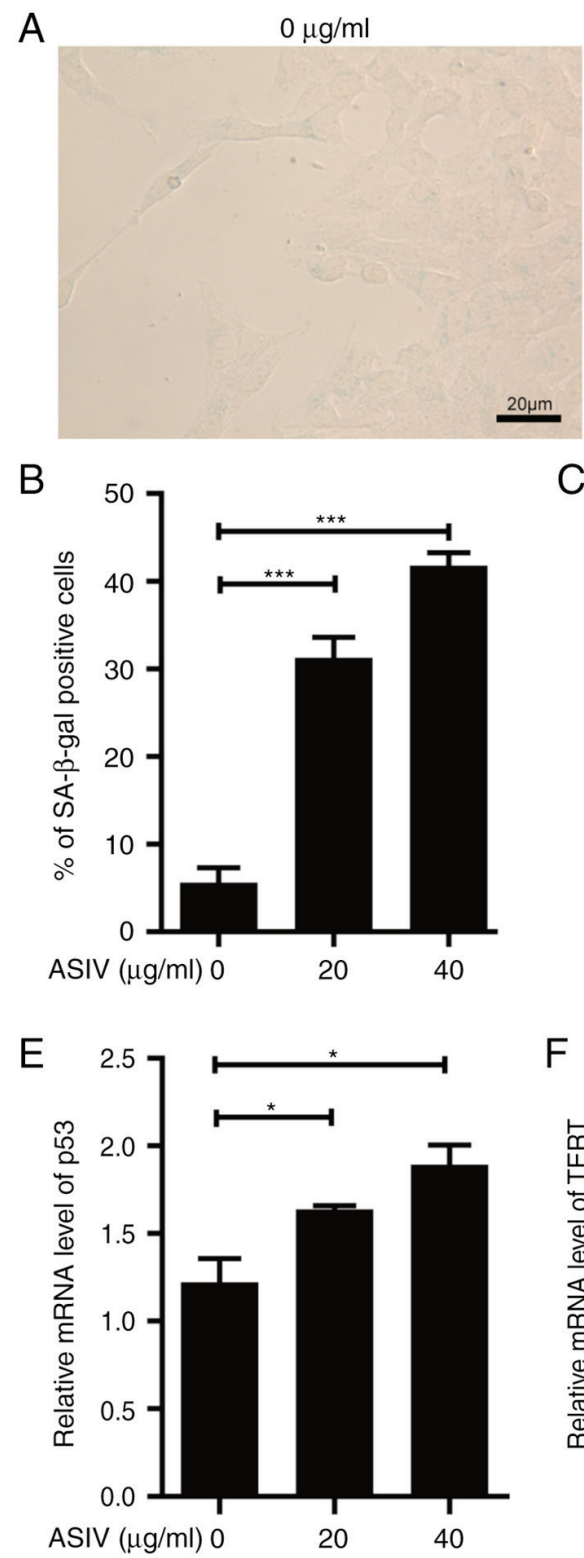

$20 \mu \mathrm{g} / \mathrm{ml}$

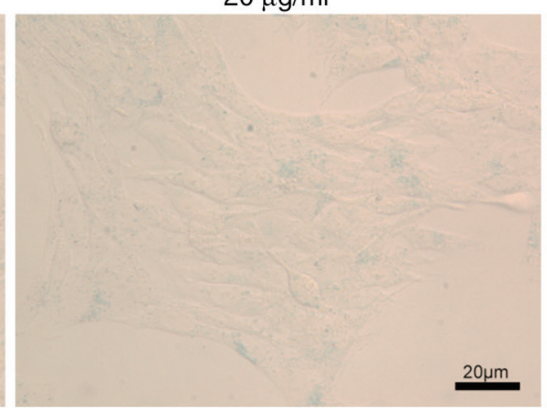

C
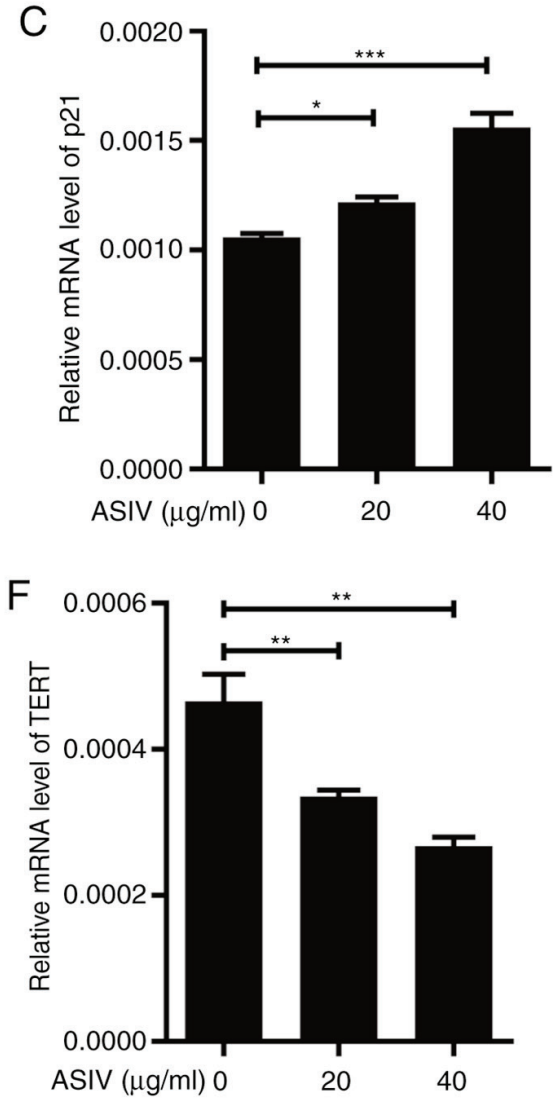

$40 \mu \mathrm{g} / \mathrm{ml}$
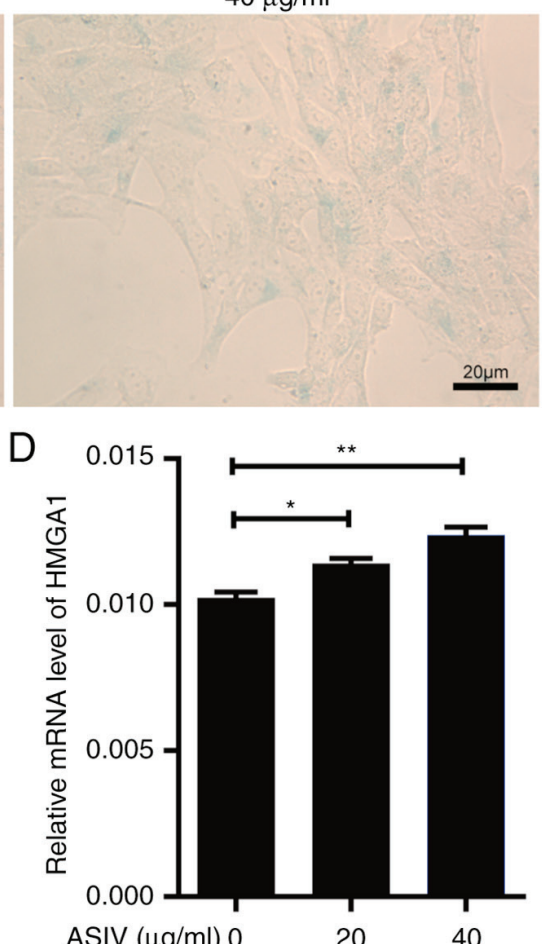

G

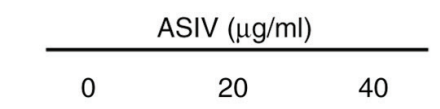

p21

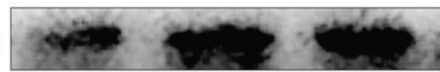

HMGA1

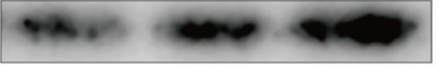

GAPDH

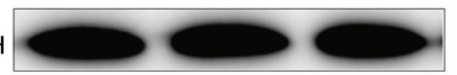

Figure 4. Evaluating cellular senescence in PDGF-BB-activated HSC-T6 treated with ASIV. (A) SA- $\beta$-gal staining of activated HSC-T6 treated with ASIV at different concentrations. Scale bar, $20 \mu \mathrm{m}$. (B) The percentage of SA- $\beta$-gal-positive HSC-T6 from (A). (C-F) The relative mRNA levels of (C) p21, (D) HMGA1, (E) p53 and (F) TERT. (G) The protein levels of p21 and HMGA1. " $\mathrm{P}<0.05,{ }^{* *} \mathrm{P}<0.01$ and ${ }^{* * *} \mathrm{P}<0.001$. ASIV, astragaloside IV; HMGA1, high-mobility group AT-hook 1; PDGF-BB, platelet-derived growth factor-BB; SA- $\beta$-gal, senescence-associated $\beta$-galactosidase; TERT, telomerase reverse transcriptase.

that cellular senescence is involved in the upregulation of p53 (42). In particular, HSCs in $\mathrm{p} 53^{-/-}$mice exhibited senescence inhibition (8), and the knockdown of p53 in activated HSCs suppressed the expression of $\mathrm{p} 21$, which lead to cellular senescence (43). In the present study, ASIV significantly increased the expression of p21 and p53 in PDGF-BB-activated HSC-T6, which indicated that cell senescence was induced. In addition, ASIV enhanced the expression of the senescence marker HMGA1 and activity of SA- $\beta$-gal, which have been reported to result from cellular senescence $(11,13)$. By contrast, telomere shortening is a driving force behind replicative senescence (44), and TERT is involved in the maintenance of telomere length (45). ASIV treatment suppressed the mRNA expression of TERT in PDGF-BB-activation HSC-T6 in the present study. Taken together, these findings suggests that ASIV upregulated the expression of senescence markers, concomitant with downregulating fibrosis markers in activated HSC-T6 to attenuate fibrosis.

Apoptosis is involved in the resolution of hepatic fibrosis through a variety of intracellular signaling pathways (46). A large number of experimental and clinical chemotherapeutic agents including the active components of Traditional Chinese Medicines have been applied to inhibit hepatic fibrosis by inducing HSC apoptosis (47-49). ASIV has been demonstrated to induce apoptosis in osteosarcoma (50) and vascular smooth muscle cells (51). Data from the present study demonstrated that ASIV promoted apoptosis but did not affect necrotic cell death in PDGF-BB-activated HSC-T6. Crosstalk between cellular senescence and apoptosis contributes to the inhibition of HSCs activation (52). Therefore, these observations suggested that ASIV suppressed the activation of HSC-T6 by promoting cellular senescence and apoptosis. 
A

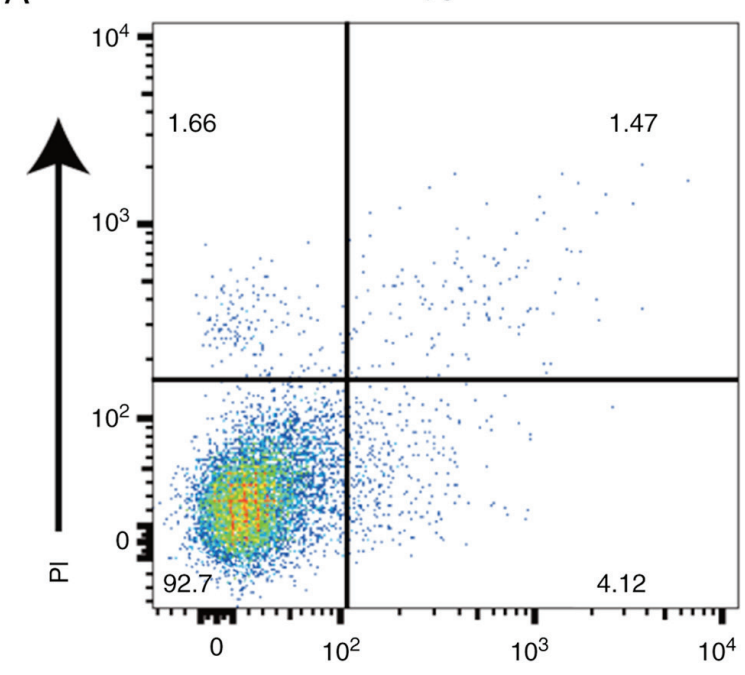

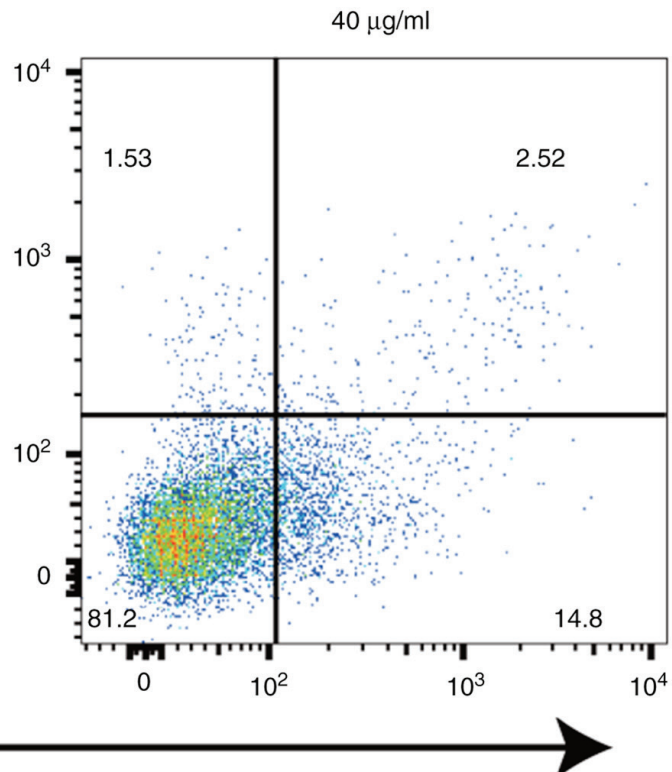

C
B

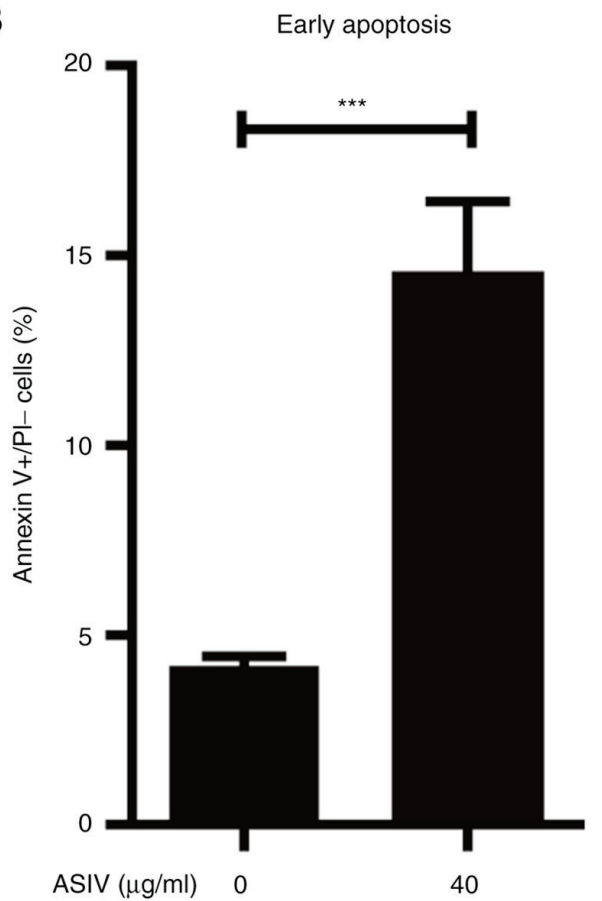

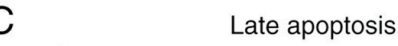

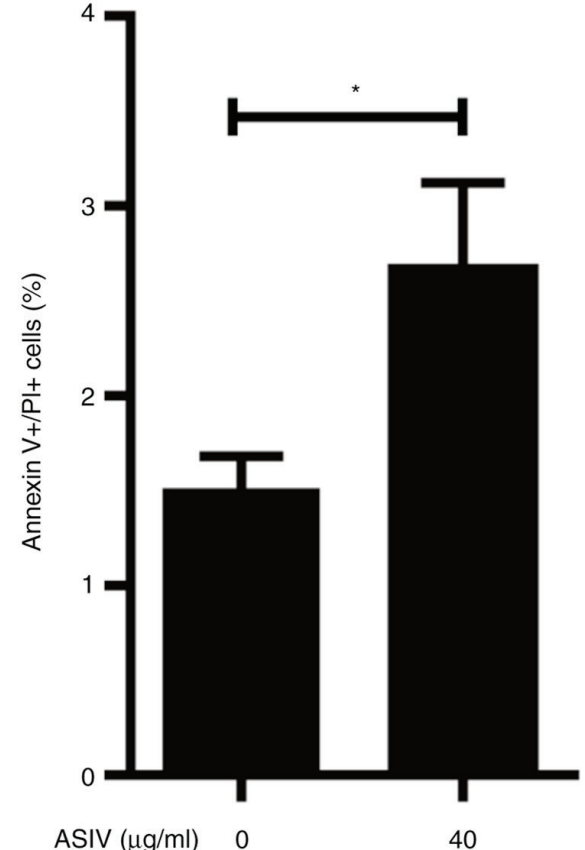

Figure 5. Analyzing apoptosis of platelet-derived growth factor-BB-activated HSC-T6 treated with ASIV. (A) Apoptosis of activated-HSC-T6 treated with 0 and $40 \mu \mathrm{g} / \mathrm{ml}$ ASIV was stained with Annexin V-APC/PI and analyzed using flow cytometry. (B and C) histogram quantifying the percentage of (B) early and (C) late apoptotic cells from (A). ${ }^{*} \mathrm{P}<0.05$ and ${ }^{* * *} \mathrm{P}<0.001$. APC, allophycocyanin; ASIV, astragaloside IV; PI, propidium iodide.

A previous study demonstrated that $\mathrm{NF}-\kappa \mathrm{B}$ signaling contributes to senescence, whereas decreasing the expression of NF- $\kappa B$ components can bypass senescence (14). The main protein components that makes up the $\mathrm{NF}-\kappa \mathrm{B}$ transcription factor include RelA/p65, RelB, c-Rel, p52 (NF-кB2) and

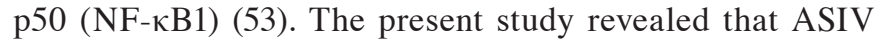
treatment upregulated the expression of p65, p52 and p50 in PDGF-BB-activated HSC-T6; RelB and c-Rel were undetectable possibly because of low expression. This result suggested that ASIV increased NF- $\kappa \mathrm{B}$ activity by upregulating the expression of $\mathrm{NF}-\kappa \mathrm{B}$ components. In unstimulated cells, inactive $\mathrm{NF}-\kappa \mathrm{B}$ heterodimers are sequestered into the cytoplasm by associating with $\mathrm{I} \kappa \mathrm{B}$ proteins. In stimuli-activated cells, the IKK complex induces the phosphorylation and degradation of $\mathrm{I} \kappa \mathrm{B}$, causing $\mathrm{NF}-\kappa \mathrm{B}$ heterodimers to be released and translocated into the nucleus (54). In the present study, ASIV treatment upregulated the expression of IKK $\alpha$ and downregulated $\mathrm{I} \kappa \mathrm{B} \alpha$. This further indicated that ASIV promoted HSCs senescence by upregulating the $\mathrm{NF}-\kappa \mathrm{B}$ signaling pathway. In addition, ASIV induced apoptosis in activated HSCs, which indicated a positive association between apoptosis and NF- $\kappa \mathrm{B}$ signaling activation in this cell type. This observation is consistent with previous studies, where compounds including flavokawain B (55), daunorubicin (55), sodium benzoate (56) and nicotine (57) have been reported to induce apoptosis by activating NF- $\kappa \mathrm{B}$ signaling. The present study hypothesized 

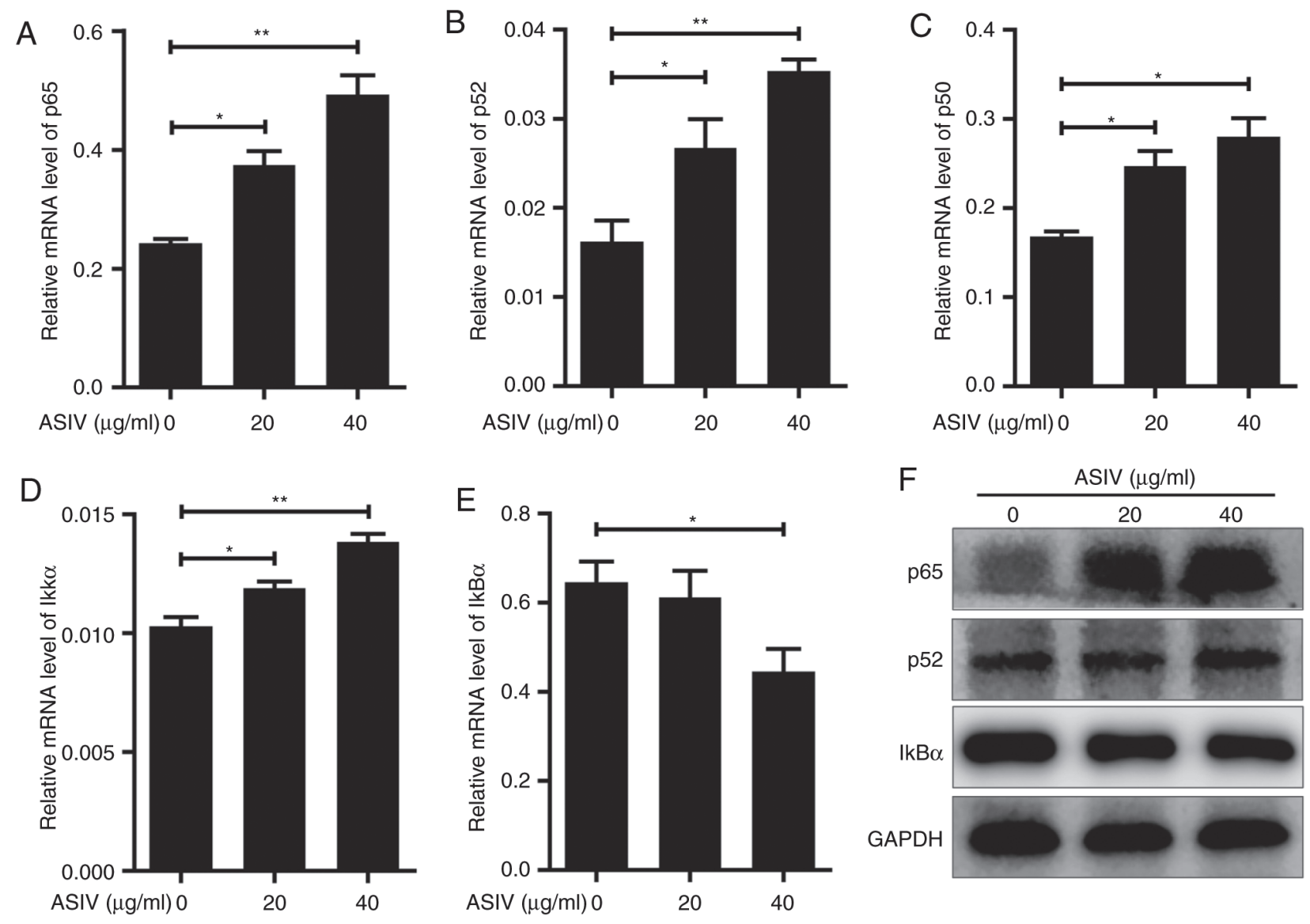

Figure 6. The expression of components in the NF- $\mathrm{\kappa B}$ pathway in platelet-derived growth factor-BB-activated HSC-T6 treated with ASIV. (A-E) The relative

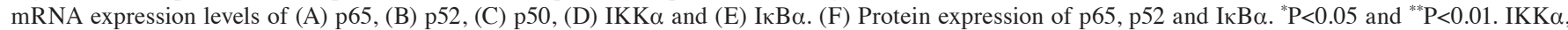

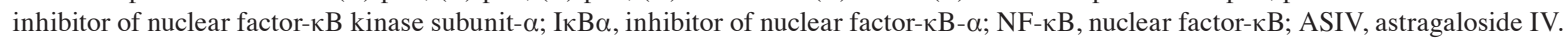

that ASIV promoted cellular senescence and apoptosis through regulating expression of factors in $\mathrm{NF}-\kappa \mathrm{B}$ signaling pathway.

PDGF-BB, a mitogen and fibrogenic cytokine, activates HSCs effectively through intracellular signaling pathways including Ras/Raf/MEK, PI3K/Akt, STATs, Rho/ROCK and $\mathrm{NF}-\kappa \mathrm{B}$ (58). A number of preclinical and clinical investigations were performed to suppress hepatic fibrosis by targeting PDGF signaling. In particular, silybin has been demonstrated to exert anti-fibrotic effects by inhibiting the phosphorylation of Raf, MEK and ERK (59), whereas celecoxib promoted HSC apoptosis by suppressing Akt activation (60). A. membranaceus has been widely used to treat hepatic fibrosis or cirrhosis in China (20). However, its molecular anti-fibrotic mechanism remains unclear. ASIV, extracted from the plant A. membranaceus, significantly enhanced the $\mathrm{NF}-\kappa \mathrm{B}$ signaling pathway. Results from the present study provided useful indications that A. membranaceus may be capable of alleviating hepatic fibrosis and cirrhosis possibly by activating the $N F-\kappa B$ signaling pathway, resulting in HSC senescence and apoptosis. Therefore, it is worth exploring the comprehensive anti-fibrotic mechanism of ASIV to design combination therapies using ASIV and clinical medicine in treating hepatic fibrosis or cirrhosis.

\section{Acknowledgements}

Not applicable.

\section{Funding}

This research project was supported by grants from The National Natural Science Foundation of China (grant no. 81573860), Science and Technology Research Program of Chongqing Municipal Education Commission (grant no. KJQN201800432) and China Postdoctoral Science Foundation (grant no. 2018M633330).

\section{Availability of data and materials}

The datasets used and/or analyzed during the present study are available from the corresponding author on reasonable request.

\section{Authors' contributions}

ZC performed the experiments. ZC, YL and WC designed the study and wrote the manuscript. GW collected the samples. LY, ZP, SP, JC and JW analyzed the data and interpreted the results. All authors read and approved the final manuscript.

\section{Ethics approval and consent to participate}

Not applicable.

\section{Patient consent for publication}

Not applicable. 


\section{Competing interests}

The authors declare that they have no competing interests.

\section{References}

1. Sun M and Kisseleva T: Reversibility of liver fibrosis. Clin Res Hepatol Gastroenterol 39 (Suppl 1): S60-S63, 2015.

2. Albanis E and Friedman SL: Hepatic fibrosis. Pathogenesis and principles of therapy. Clin Liver Dis 5: 315-334, v-vi, 2001.

3. Duarte S, Baber J, Fujii T and Coito AJ: Matrix metalloproteinases in liver injury, repair and fibrosis. Matrix Biol 44-46: 147-156, 2015.

4. Bitto N, Liguori E and La Mura V: Coagulation, microenvironment and liver fibrosis. Cells 7: E85, 2018.

5. Hernandez-Gea V and Friedman SL: Pathogenesis of liver fibrosis. Annu Rev Pathol 6: 425-456, 2011.

6. Higashi T, Friedman SL and Hoshida Y: Hepatic stellate cells as key target in liver fibrosis. Adv Drug Deliv Rev 121: 27-42, 2017.

7. Wong L, Yamasaki G, Johnson RJ and Friedman SL: Induction of beta-platelet-derived growth factor receptor in rat hepatic lipocytes during cellular activation in vivo and in culture. J Clin Invest 94: 1563-1569, 1994

8. Krizhanovsky V, Yon M, Dickins RA, Hearn S, Simon J, Miething C, Yee H, Zender L and Lowe SW: Senescence of activated stellate cells limits liver fibrosis. Cell 134: 657-667, 2008.

9. Kong X, Feng D, Wang H, Hong F, Bertola A, Wang FS and Gao B: Interleukin-22 induces hepatic stellate cell senescence and restricts liver fibrosis in mice. Hepatology 56: 1150-1159, 2012.

10. Zhang Z, Yao Z, Zhao S, Shao J, Chen A, Zhang F and Zheng S: Interaction between autophagy and senescence is required for dihydroartemisinin to alleviate liver fibrosis. Cell Death Dis 8: e2886, 2017.

11. Lee BY, Han JA, Im JS, Morrone A, Johung K, Goodwin EC, Kleijer WJ, DiMaio D and Hwang ES: Senescence-associated beta-galactosidase is lysosomal beta-galactosidase. Aging Cell 5: 187-195, 2006.

12. Leontieva OV and Blagosklonny MV: CDK4/6-inhibiting drug substitutes for p21 and p16 in senescence: Duration of cell cycle arrest and MTOR activity determine geroconversion. Cell Cycle 12: 3063-3069, 2013

13. Narita M, Narita M, Krizhanovsky V, Nuñez S, Chicas A, Hearn SA, Myers MP and Lowe SW: A novel role for high-mobility group a proteins in cellular senescence and heterochromatin formation. Cell 126: 503-514, 2006.

14. Chien Y, Scuoppo C, Wang X, Fang X, Balgley B, Bolden JE, Premsrirut P, Luo W, Chicas A, Lee CS, et al: Control of the senescence-associated secretory phenotype by NF- $\kappa \mathrm{B}$ promotes senescence and enhances chemosensitivity. Genes Dev 25: 2125-2136, 2011

15. Osorio FG, Lopez-Otin C and Freije JM: NF- $\kappa$ B in premature aging. Aging 4: 726-727, 2012.

16. Duci SB, Arifi HM, Ahmeti HR, Zatriqi VK, Buja ZA, Hoxha ET and Mekaj AY: Outcomes of older adults with burn injury: University clinical center of kosovo. World J Plast Surg 4: 153-158, 2015.

17. Elmore S: Apoptosis: A review of programmed cell death. Toxicol Pathol 35: 495-516, 2007.

18. Arur S, Uche UE, Rezaul K, Fong M, Scranton V, Cowan AE, Mohler W and Han DK: Annexin I is an endogenous ligand that mediates apoptotic cell engulfment. Dev Cell 4: 587-598, 2003.

19. Mallat A and Lotersztajn S: Reversion of hepatic stellate cell to a quiescent phenotype: From myth to reality? J Hepatol 59: 383-386, 2013

20. Sun WY, Wang L, Liu H, Li X and Wei W: A standardized extract from Paeonia lactiflora and Astragalus membranaceus attenuates liver fibrosis induced by porcine serum in rats. Int J Mol Med 29: 491-498, 2012.

21. Liu Y, Liu J, Wu KX, Guo XR and Tang ZH: A rapid method for sensitive profiling of bioactive triterpene and flavonoid from Astragalus mongholicus and Astragalus membranaceus by ultra-pressure liquid chromatography with tandem mass spectrometry. J Chromatogr B Analyt Technol Biomed Life Sci 1085 110-118, 2018.

22. Mei M, Tang F, Lu M, He X, Wang H, Hou X, Hu J, Xu C and Han R: Astragaloside IV attenuates apoptosis of hypertrophic cardiomyocyte through inhibiting oxidative stress and calpain-1 activation. Environ Toxicol Pharmacol 40: 764-773, 2015.
23. Hao M, Liu Y, Chen P, Jiang H and Kuang HY: Astragaloside IV protects RGC-5 cells against oxidative stress. Neural Regen Res 13: 1081-1086, 2018.

24. Wang S, Mou J, Cui L, Wang X and Zhang Z: Astragaloside IV inhibits cell proliferation of colorectal cancer cell lines through down-regulation of B7-H3. Biomed Pharmacother 102: 1037-1044, 2018.

25. Wang PP, Luan JJ, Xu WK, Wang L, Xu DJ, Yang CY, Zhu YH and Wang YQ: Astragaloside IV downregulates the expression of MDR1 in Bel7402/FU human hepatic cancer cells by inhibiting the JNK/cJun/AP1 signaling pathway. Mol Med Rep 16: 2761-2766, 2017.

26. Li LC, Xu L, Hu Y, Cui WJ, Cui WH, Zhou WC and Kan LD: Astragaloside IV improves bleomycin-induced pulmonary fibrosis in rats by attenuating extracellular matrix deposition. Front Pharmacol 8: 513, 2017.

27. Qian W, Cai X, Qian Q, Zhang W and Wang D: Astragaloside IV modulates TGF- $\beta 1$-dependent epithelial-mesenchymal transition in bleomycin-induced pulmonary fibrosis. J Cell Mol Med 22: 4354-4364, 2018.

28. Wan Y, Xu L, Wang Y, Tuerdi N, Ye M and Qi R: Preventive effects of astragaloside IV and its active sapogenin cycloastragenol on cardiac fibrosis of mice by inhibiting the NLRP3 inflammasome. Eur J Pharmacol 833: 545-554, 2018.

29. Chen P, Xie Y, Shen E, Li GG, Yu Y, Zhang CB, Yang Y, Zou Y, $\mathrm{Ge}$ J, Chen R and Chen H: Astragaloside IV attenuates myocardial fibrosis by inhibiting TGF- $\beta 1$ signaling in coxsackievirus B3-induced cardiomyopathy. Eur J Pharmacol 658: 168-174, 2011.

30. Xu W, Shao X, Tian L, Gu L, Zhang M, Wang Q, Wu B, Wang L, Yao J, Xu X, et al: Astragaloside IV ameliorates renal fibrosis via the inhibition of mitogen-activated protein kinases and antiapoptosis in vivo and in vitro. J Pharmacol Exp Ther 350: 552-562, 2014.

31. Wang L, Chi YF, Yuan ZT, Zhou WC, Yin PH, Zhang XM, Peng $\mathrm{W}$ and Cai $\mathrm{H}$ : Astragaloside IV inhibits renal tubulointerstitial fibrosis by blocking TGF- $\beta /$ Smad signaling pathway in vivo and in vitro. Exp Biol Med (Maywood) 239: 1310-1324, 2014.

32. Liu H, Wei W, Sun WY and Li X: Protective effects of astragaloside IV on porcine-serum-induced hepatic fibrosis in rats and in vitro effects on hepatic stellate cells. J Ethnopharmacol 122: 502-508, 2009

33. Ping J, Li JT, Liao ZX, Shang L and Wang H: Indole-3-carbinol inhibits hepatic stellate cells proliferation by blocking NADPH oxidase/reactive oxygen species/p38MAPK pathway. Eur J Pharmacol 650: 656-662, 2011.

34. Li X, Wang X, Han C, Wang X, Xing G, Zhou L, Li G and Niu Y: Astragaloside IV suppresses collagen production of activated hepatic stellate cells via oxidative stress-mediated p38 MAPK pathway. Free Radic Biol Med 60: 168-176, 2013.

35. Livak KJ and Schmittgen TD: Analysis of relative gene expression data using real-time quantitative PCR and the 2(-Delta Delta C(T)) method. Methods 25: 402-408, 2001.

36. Tsuchida T and Friedman SL: Mechanisms of hepatic stellate cell activation. Nat Rev Gastroenterol Hepatol 14: 397-411, 2017.

37. Huang Y, Deng X and Liang J: Modulation of hepatic stellate cells and reversibility of hepatic fibrosis. Exp Cell Res 352: 420-426, 2017.

38. de Oliveira da Silva B, Ramos LF and Moraes KCM: Molecular interplays in hepatic stellate cells: Apoptosis, senescence, and phenotype reversion as cellular connections that modulate liver fibrosis. Cell Bio Int 41: 946-959, 2017.

39. Kang C, Xu Q, Martin TD, Li MZ, Demaria M, Aron L, Lu T, Yankner BA, Campisi J and Elledge SJ: The DNA damage response induces inflammation and senescence by inhibiting autophagy of GATA. Science 349: aaa5612, 2015.

40. Thirukkumaran C, Shi ZQ, Thirukkumaran P, Luider J, Kopciuk K, Spurrell J, Elzinga K and Morris D: PUMA and NF- $\kappa \mathrm{B}$ are cell signaling predictors of reovirus oncolysis of breast cancer. PLoS One 12: e0168233, 2017.

41. Zoubek ME, Trautwein C and Strnad P: Reversal of liver fibrosis: From fiction to reality. Best Pract Res Clin Gastroenterol 31: 129-141, 2017.

42. Rufini A, Tucci P, Celardo I and Melino G: Senescence and aging: The critical roles of p53. Oncogene 32: 5129-5143, 2013.

43. Chen J, Pan J, Wang J, Song K, Zhu D, Huang C and Duan Y: Soluble egg antigens of schistosoma japonicum induce senescence in activated hepatic stellate cells by activation of the STAT3/p53/p21 pathway. Sci Rep 6: 30957, 2016. 
44. Campisi J and d'Adda di Fagagna F: Cellular senescence: When bad things happen to good cells. Nat Rev Mol Cell Biol 8: 729-740, 2007.

45. Zhao Z, Pan X, Liu L and Liu N: Telomere length maintenance, shortening, and lengthening. J Cell Physiol 229: 1323-1329, 2014.

46. Duval F, Moreno-Cuevas JE, Gonzalez-Garza MT, Rodriguez-Montalvo C and Cruz-Vega DE: Liver fibrosis and protection mechanisms action of medicinal plants targeting apoptosis of hepatocytes and hepatic stellate cells. Adv Pharmacol Sci 2014: 373295, 2014.

47. Meng D, Li Z, Wang G, Ling L, Wu Y and Zhang C: Carvedilol attenuates liver fibrosis by suppressing autophagy and promoting apoptosis in hepatic stellate cells. Biomed Pharmacother 108: 1617-1627, 2018.

48. Senoo T, Sasaki R, Akazawa Y, Ichikawa T, Miuma S, Miyaaki H, Taura N and Nakao K: Geranylgeranylacetone attenuates fibrogenic activity and induces apoptosis in cultured human hepatic stellate cells and reduces liver fibrosis in carbon tetrachloride-treated mice. BMC Gastroenterol 18: 34, 2018.

49. Kuo LM, Chen PJ, Sung PJ, Chang YC, Ho CT, Wu YH and Hwang TL: The bioactive extract of pinnigorgia sp. induces apoptosis of hepatic stellate cells via ROS-ERK/JNK-caspase-3 signaling. Mar Drugs 16: E19, 2018.

50. Hu T, Fei Z and Wei N: Chemosensitive effects of astragaloside IV in osteosarcoma cells via induction of apoptosis and regulation of caspase-dependent Fas/FasL signaling. Pharmacol Rep 69: 1159-1164, 2017.

51. Yuan W, Zhang Y, Ge Y, Yan M, Kuang R and Zheng X: Astragaloside IV inhibits proliferation and promotes apoptosis in rat vascular smooth muscle cells under high glucose concentration in vitro. Planta Med 74: 1259-1264, 2008.

52. Childs BG, Baker DJ, Kirkland JL, Campisi J and van Deursen JM: Senescence and apoptosis: Dueling or complementary cell fates? EMBO Rep 15: 1139-1153, 2014.
53. Xia Y, Shen S and Verma IM: NF- $\kappa B$, an active player in human cancers. Cancer Immunol Res 2: 823-830, 2014.

54. Hayden MS and Ghosh S: Regulation of NF- $\mathrm{BB}$ by TNF family cytokines. Semin Immunol 26: 253-266, 2014.

55. Lee JJ, Koh KN, Park CJ, Jang S, Im HJ and Kim N: The combination of flavokawain $\mathrm{B}$ and daunorubicin induces apoptosis in

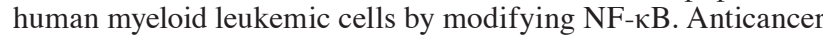
Res 38: 2771-2778, 2018.

56. Yilmaz B and Karabay AZ: Food additive sodium benzoate $(\mathrm{NaB})$ activates NFkB and induces apoptosis in HCT116 cells. Molecules 23: E723, 2018.

57. Kim CS, Choi JS, Joo SY, Bae EH, Ma SK, Lee J and Kim SW: Nicotine-induced apoptosis in human renal proximal tubular epithelial cells. PLoS One 11: e0152591, 2016.

58. Ying HZ, Chen Q, Zhang WY, Zhang HH, Ma Y, Zhang SZ, Fang $\mathrm{J}$ and $\mathrm{Yu} \mathrm{CH}$ : PDGF signaling pathway in hepatic fibrosis pathogenesis and therapeutics (Review). Mol Med Rep 16: 7879-7889, 2017.

59. Trappoliere M, Caligiuri A, Schmid M, Bertolani C, Failli P, Vizzutti F, Novo E, di Manzano C, Marra F, Loguercio C and Pinzani M: Silybin, a component of sylimarin, exerts anti-inflammatory and anti-fibrogenic effects on human hepatic stellate cells. J Hepatol 50: 1102-1111, 2009.

60. Paik YH, Kim JK, Lee JI, Kang SH, Kim DY, An SH, Lee SJ, Lee DK, Han KH, Chon CY, et al: Celecoxib induces hepatic stellate cell apoptosis through inhibition of Akt activation and suppresses hepatic fibrosis in rats. Gut 58: 1517-1527, 2009.

This work is licensed under a Creative Commons Attribution-NonCommercial-NoDerivatives 4.0 International (CC BY-NC-ND 4.0) License. 